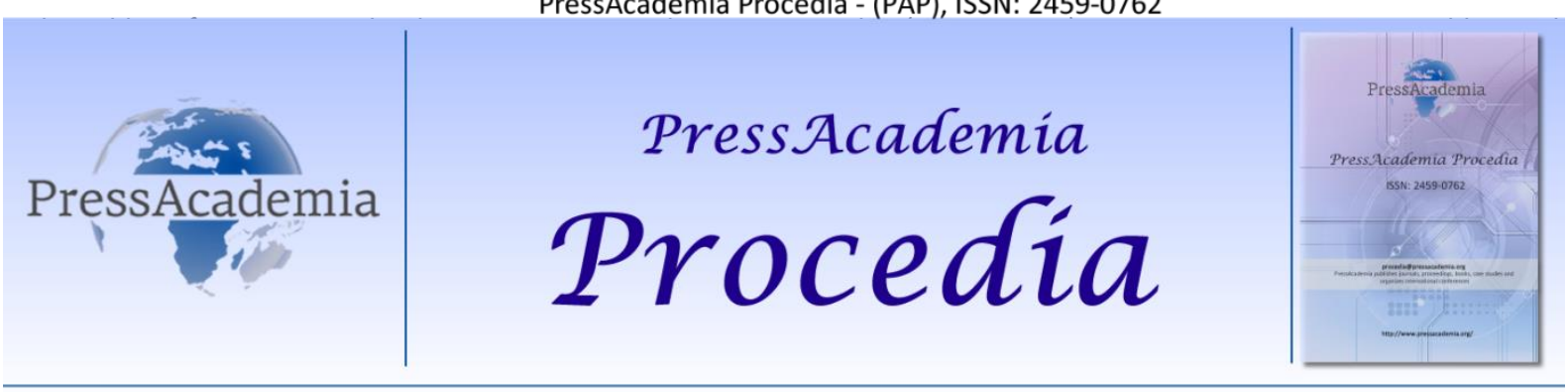

2nd World Conference on Technology, Innovation and Entrepreneurship

May 12- 14, 2017, Istanbul, Turkey. Edited by Sefer Şener

\title{
CONSIDERING AIR DENSITY EFFECT ON MODELLING WIND FARM POWER CURVE USING SITE MEASUREMENTS
}

\section{DOI: 10.17261/Pressacademia.2017.619 \\ PAP-WCTIE-V.5-2017(57)-p.420-430}

\author{
Ceyhun Yildiz ${ }^{1}$, Mustafa Tekin ${ }^{2}$, Ahmet Gani ${ }^{3}$, O.Fatih Kececioglu ${ }^{4}$, Hakan Acikgoz ${ }^{5}$, Mustafa Sekkeli ${ }^{6}$ \\ ${ }^{1}$ Graduate School of Natural and Applied Sciences, K.Maraş Sütçü Imam University. cyildiz@ksu.edu.tr \\ 2Department of Electrical and Electronics Eng., Faculty of Eng. and Architecture, K.Maraş Sütçü İmam University. mustafatekin@ksu.edu.tr \\ 3Department of Electrical and Electronics Eng., Faculty of Eng. and Architecture, K.Maraş Sütçü İmam University. agani@ksu.edu.tr \\ 4Department of Electrical and Electronics Eng., Faculty of Eng. and Architecture, K.Maraş Sütçü İmam University. fkececioglu@ksu.edu.tr \\ 5Graduate School of Natural and Applied Sciences, K.Maraş Sütçü Imam University. hakanacikgoz@ksu.edu.tr \\ 6Department of Electrical and Electronics Eng., Faculty of Eng. and Architecture, K.Maraş Sütçü Imam University. msekkeli@ksu.edu.tr
}

\begin{abstract}
Manufacturers develop power curves for their wind turbines. Customers use these wind turbine power curves for wind farm planning and estimating nearly total production of planned plant. When wind farm is installed and connected to the grid, these power curves are not useful. In literacy, researchers proposed wind turbine power curve measurement methods to obtain an accurate power curve for turbine on site. But it is not easy to develop power curves for clusters of wind turbines. Developing a single power curve for a wind farm slightly simplifies this problem. Accurate wind farm power curve is a very useful tool for converting wind speed forecasts to power. Also plant owner can use this tool to detect anomalous operations. In this study we developed and tested wind farm power curves by using real site measurements. Two different methods are used to develop power curves. They are polynomial curve fitting and mean bins method. Wind speed and power output relation is investigated. A method is proposed to add effect of air density on power curve. Developed power curve has two inputs. They are hourly mean wind speed and air density values. This approach uses variable air density in calculation of wind farm power output. Results of this study showed that performance of mean bins method is better than polynomial curve fitting. Also proposed air density effect adding method improves performances of obtained power curves.
\end{abstract}

Keywords: Wind farm, power curve, air density effect, mean power bins, wind turbine power curve.

\section{INTRODUCTION}

Over the last decades wind energy has been the fastest growing renewable energy[1]. Promoting policies of countries and decrease in installation costs increased the total installed capacity of wind power all around the world. It is well known that wind energy has variable, uncertain nature and it is not easy to balance power system with high wind power penetration [2]. Transmission system operators must ensure and maintain the balance between supply and demand in their electrical grids. Within this scope numerous studies on wind power forecast have been carried out. Forecasts help TSOs to create generation plan.

Wind energy forecast systems use wind farm power curves to transform forecasted wind speeds to electrical power. So accuracy of power curve has an impact on performance of the forecast. Developing a power curve for a wind farm is not an easy process. Because wind farms will have clusters of wind turbines spread over a large area and site conditions differs cluster to cluster. Also air density, topographical obstacles, wake effects, wind direction etc. effects wind speed-power output relation.

It is necessary to have accurate site measurements to develop a wind farm power curve and to evaluate the performance of power curve. Hard weather conditions like icing, very high wind speeds etc. make difficult get accurate measurement data. 
These measurements must also include wind farm power output, wind speed, wind direction, pressure, temperature and humidity. Other meteorological data air density, is function of pressure, temperature and humidity [3].

A lot of study on wind farm power curve development have focused wind and power relation [4-10]. In literacy small number of studies investigated effect of air density on power curves. These studies have different conclusions about considering the effect of air density. Farkas [11] suggests considering air density in wind power calculations.On the other hand, according to Wan and at all. [12] using air density as an additional input in calculation didn't improve the performance. Also [14]standard on wind turbine performance test proposed normalizing wind power data with constant measured mean air density.

In this study we developed a wind farm power curve. Real site measurements are used during the development and test stages. Wind speed, power output and air density data are used in calculations. Polynomial curve fitting and mean bins methods are used to develop power curves. A new method is used to assess variable air density effects.

The rest of this paper is structured as follows: Section 2 describes measurement stations; Section 3 analyzes measured data; Section 4 describes application of methods; Section 5 analyzes power curve performance; Section 6 includes conclusions of the study.

\begin{tabular}{|c|c|}
\hline \multicolumn{2}{|c|}{ Nomenclature } \\
\hline c: wind power conversion constant & $\boldsymbol{M}_{\boldsymbol{a}}:$ molar mass of dry air $(\mathrm{g} / \mathrm{mol})$ \\
\hline $\boldsymbol{h}$ : humidity $(0<\mathrm{h}<1)$ & $\boldsymbol{M}_{\mathbf{v}}:$ molar mass of dry water $(\mathrm{g} / \mathrm{mol})$ \\
\hline $\boldsymbol{p}$ : pressure $(\mathrm{Pa})$ & R: molar gas constant $\left(\mathrm{JK}^{-1} \mathrm{~mol}^{-1}\right)$ \\
\hline P: power (MW) & T: thermodynamic temperature \\
\hline Pc: power curve & $\boldsymbol{X}_{\boldsymbol{v}}$ : mole fraction of water vapour \\
\hline $\boldsymbol{P}^{v}$ : air density rejected power (MW) & Z: compressibility factor \\
\hline $\boldsymbol{t}$ : temperature $\left({ }^{0} \mathrm{C}\right)$ & $\rho$ :air density $\left(\mathrm{kg} / \mathrm{m}^{2}\right)$ \\
\hline $\boldsymbol{v}:$ wind velocity $(\mathrm{m} / \mathrm{s})$ & $\rho_{m}:$ measured air density $\left(\mathrm{kg} / \mathrm{m}^{2}\right)$ \\
\hline
\end{tabular}

\section{MEASUREMENT STATIONS}

In this study two kinds of measurement stations (electrical power and a meteorological data measurement station) are used as wind farm power curve is a result of relation between meteorological data and electrical power output of plant. Rest of this section describes measurement stations.

\subsection{Electrical Power Measurement Station}

This station is installed in the power house of the plant. Power output and it's quality are measured. Hardware of the station is composed of signal conditioner and data acquisition cards, mini pc, modem and GPS time synchronizer equipment. Power plant's sensors are used to get voltage and current values. Signal conditioner card converts raw sensor signals to suitable form for data acquisition card. After signal conditioning process data acquisition card converts these signals to numerical values. Mini PC performs calculation, communication and time synchronization algorithms. GPS time synchronizer gets accurate time data to create time label of calculated values. Simple hardware configuration of the system is given in Figure 1.

Fig. 1: Hardware Configuration of Power Measurement Station

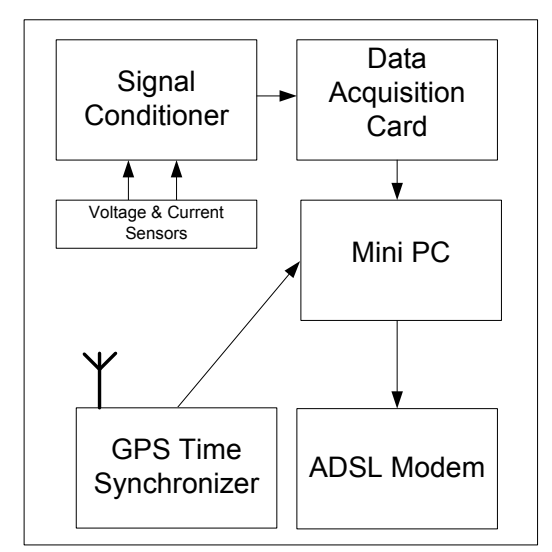


After transforming raw analog (voltage, current) measurements into numerical values, mini PC performs calculations in accordance with IEC standard numbered 61000-4-30 [13]. Simple flow chart of electrical power measurement algorithm is as follows.

\section{Fig. 2: Flow Chart of Electrical Measurement Algorithm}

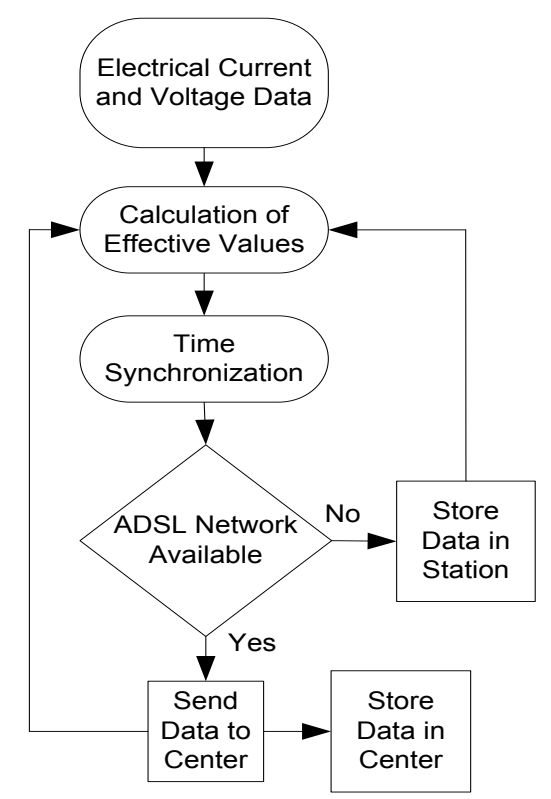

At first step of the algorithm effective values are calculated. Second step is time synchronization. After them algorithm checks network. If network is available system sends data to data center. If network is not available system stores data in measurement station.

\subsection{Meteorological Measurement Station}

Wind turbines are spread over a large area. So it is not easy to measure all turbine site's meteorology. For this reason a specific site that can represent whole plant area meteorology is selected. The hardware of the system is composed of wind speed, wind direction, pressure, humidity, temperature sensors; data logger, photo voltaic energy source system and tower. Installation is carried out in accordance with IEC standard numbered 61400-12-1 [14]. Simple hardware scheme is given in Figure 3.

Fig. 3: Schematic Expression of Meteorological Measurement Station

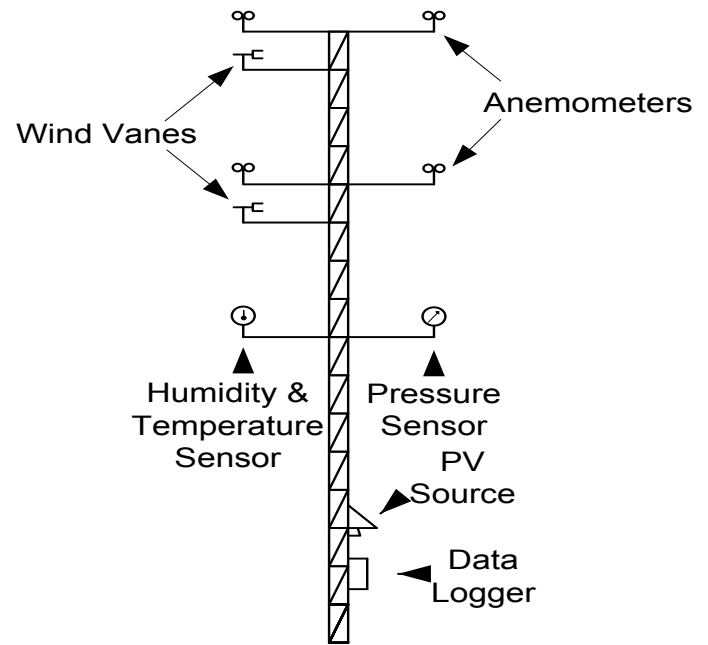


Four anemometers and two wind vanes are used to measure wind speed and direction values. Object of duplicate using of anemometer and vane is to detect malfunction operation and to get values at different altitudes. The system will check sensor measurement by comparing another sensor's value. GPS time synchronization is also used in this station and GPRS modem is used for communication. Software of this system has simple algorithm. Algorithm gets sensor data, synchronizes it with GPS time, if network is available sends data to data center if network is not available stores data in station. Data logger performs these algorithms.

\section{DEVELOPING WIND FARM POWER CURVE}

Wind farm power output and meteorological data relation gives power curve of the plant. First step of the investigation is to obtain accurate data set. Data set comprises wind speed, air density and power output of wind farm. Air density is function of three types of measurements (air pressure, temperature and relative humidity). Detailed calculation of air density is given in this section. Second step is applying methods to obtain relation between meteorological data and power output. In this study polynomial curve fitting, mean bin methods are used. Third step, performance evaluation is given in the next Section 4

\subsection{Meteorological and Power Data Set}

Detailed explanation of measurement stations are given in previous sections. In this section short overview of measured data and air density calculation are given. Meteorological measurements involve wind speed, temperature, air pressure and relative humidity. Fig. 4 is histogram of wind speeds and fitted Weibull curve with $k$ and $c$ parameters $(k=1.95, c=8.5)$.

Fig. 4: Wind Speed Histogram and Fitted Weibull Curve

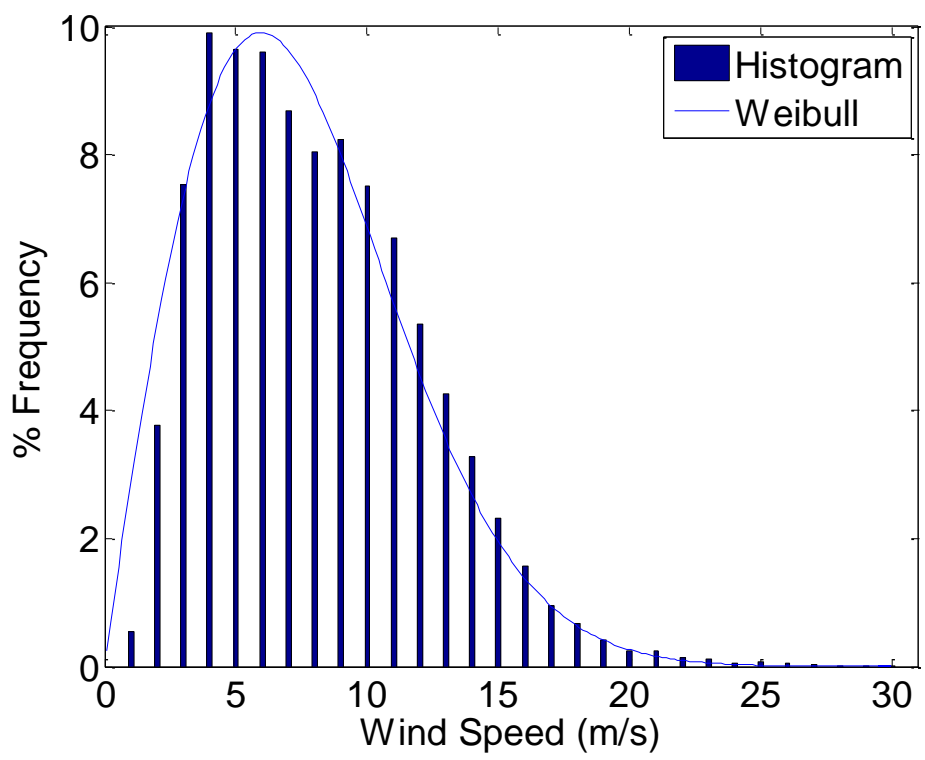

Fig. 5-7 represent available \% humidity, air pressure in $(\mathrm{mb})$ and temperature in $\left(\mathrm{C}^{0}\right)$ data respectively. Because of the hard weather conditions and PV source shortage some data are not available. Measurement period involves 30553 hours as 21123 hours are available. There are five kinds of measurement sensors so it is not easy to operate them simultaneously. It is needed to have three kinds of measurements (pressure, humidity, temperature) to calculate air density also wind vane and anemometer are needed to measure wind data. So number of available data reduces. 
Fig. 5: Humidity Data

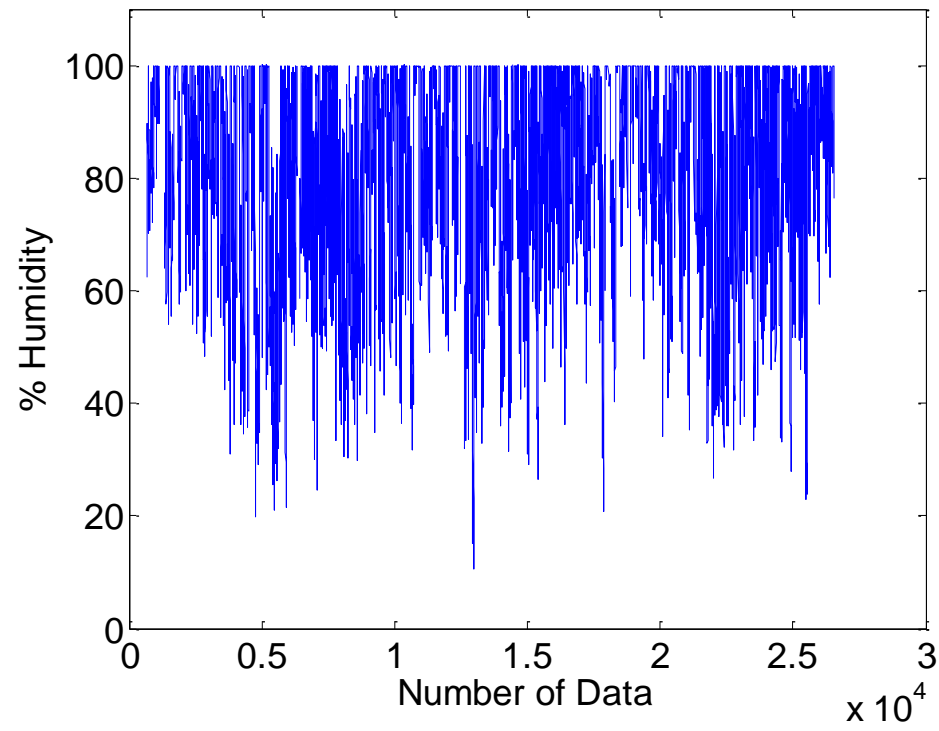

Fig. 6: Pressure Data

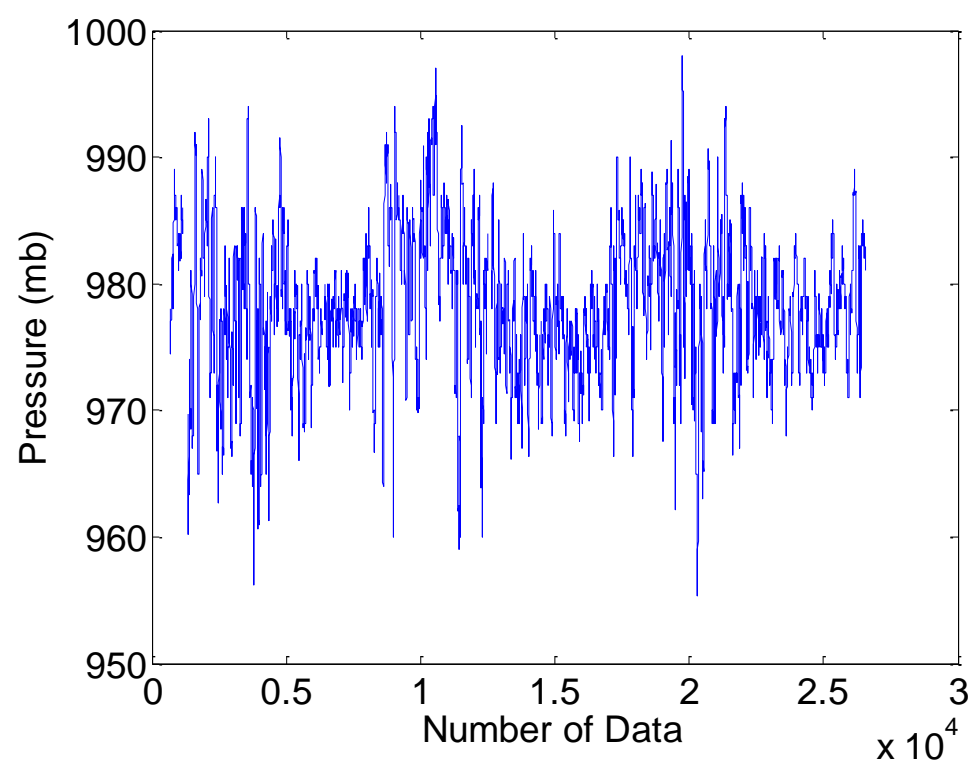


Fig. 7: Temperature Data

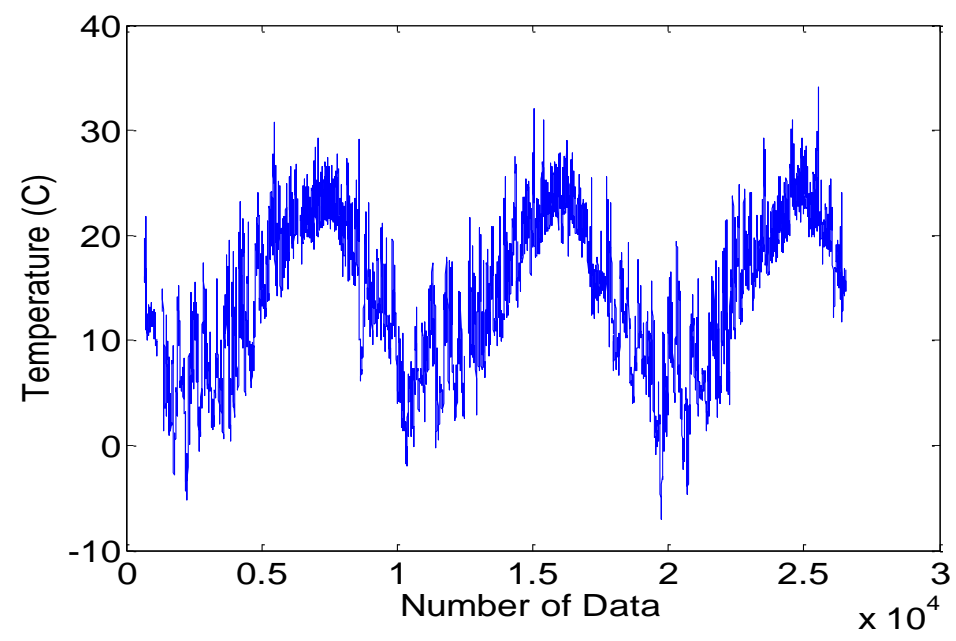

Formula of moist air density is used to calculate density of air. Formula has three variables. $t$ is temperature $\left({ }^{0} \mathrm{C}\right), p$ is air pressure $[\mathrm{Pa}], h$ is relative humidity $(0 \leq h \leq 1)$. Other parameters are constants, given in [3]. Calculated air density is as in Fig. 8.

$$
\begin{aligned}
& \rho(t, p, h)=\frac{p M_{a}}{Z(t, p, h) R T(t)}\left(1-x_{v}(\mathrm{t}, \mathrm{p}, \mathrm{h})\left[1-\frac{M_{v}}{M_{a}}\right]\right) \\
& x_{v}(t, p, h)=h\left[\alpha+\beta p+\gamma t^{2}\right] \frac{e^{\left[\mathrm{AT}(\mathrm{t})^{2}+\mathrm{BT}(\mathrm{t})+\mathrm{C}+\frac{D}{T(\mathrm{t})}\right]} P a}{p} \\
& Z(t, p, h)=1-\frac{p}{T(t)}\left(a_{0}+a_{1} t+a_{2} t^{2}+\left[\mathrm{b}_{0}+\mathrm{b}_{1} \mathrm{t}\right] \mathrm{x}_{v}+\left[\mathrm{c}_{0}+c_{1} \mathrm{t}\right] \mathrm{x}_{v}^{2}\right)+\frac{p^{2}}{T(\mathrm{t})^{2}}\left[\mathrm{~d}+\mathrm{ex}_{v}^{2}\right]
\end{aligned}
$$

\section{Fig. 8: Calculated Air Density}

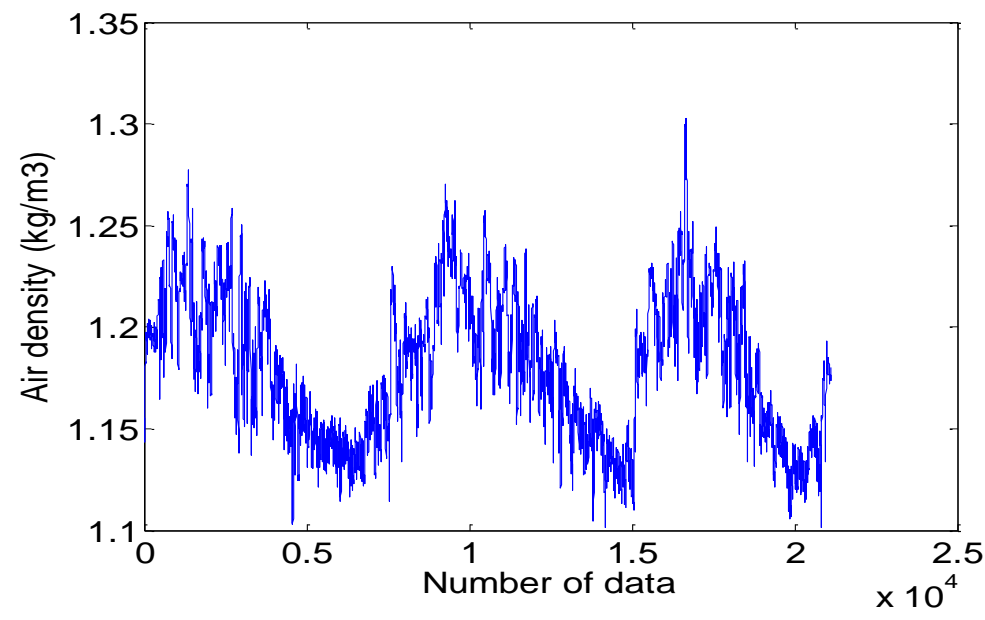


Last data set involves output powers of the plant. Wind farm has five $3 \mathrm{MW}$ wind turbines. Installed power is $15 \mathrm{MW}$. Electrical power output of the system is measured simultaneously (time synchronization between meteorological data is carried out). Total power output of the farm is as in Fig. 9.

Fig. 9: Wind Power Plant Output

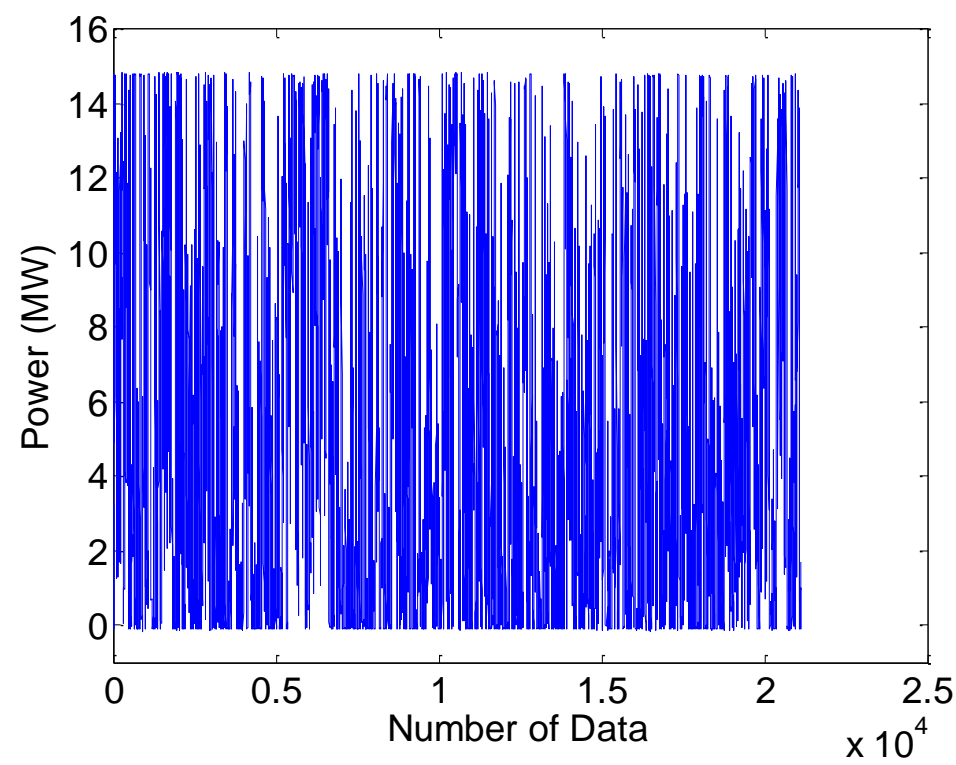

\section{APPLIED METHODS}

Before applying methods, scatter plots of wind speed-power and air density-power are created. As expected, these plots showed that relation between wind speed and power output is stronger than air density-power relation. It is known that wind speed has cubic, air density has proportional relation between power[15]. Stronger relation of wind speed is result of this situation. Scatter plots of air density-power and wind velocity-power are as in Fig. 9 and Fig. 10.

Fig. 9. Scatter Plot of Air Density-Power

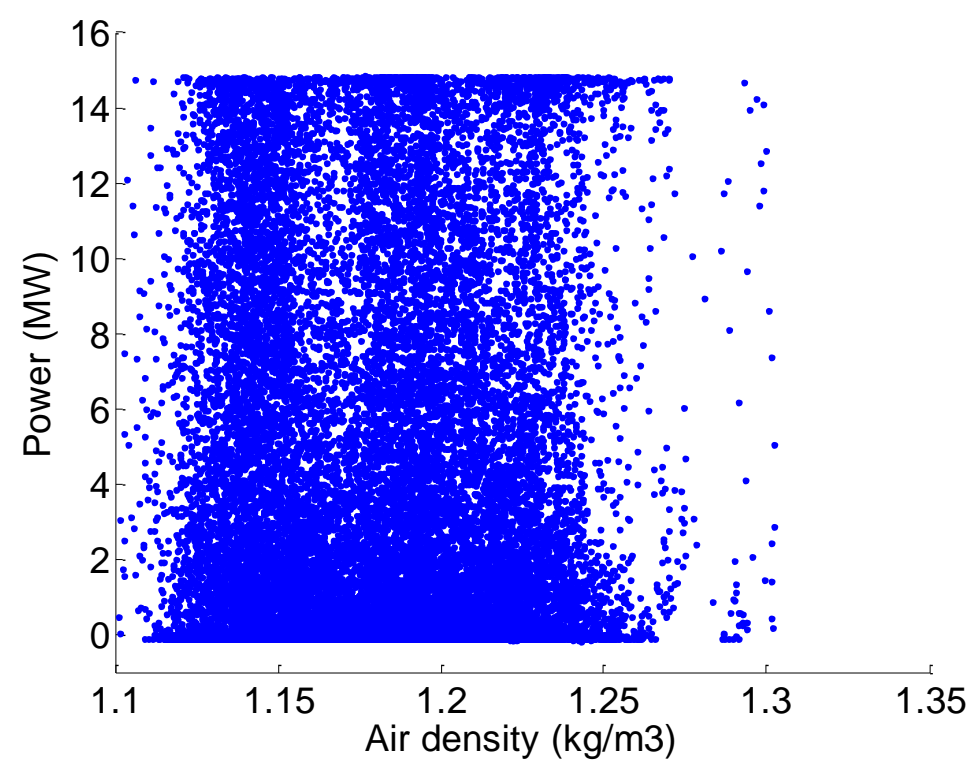




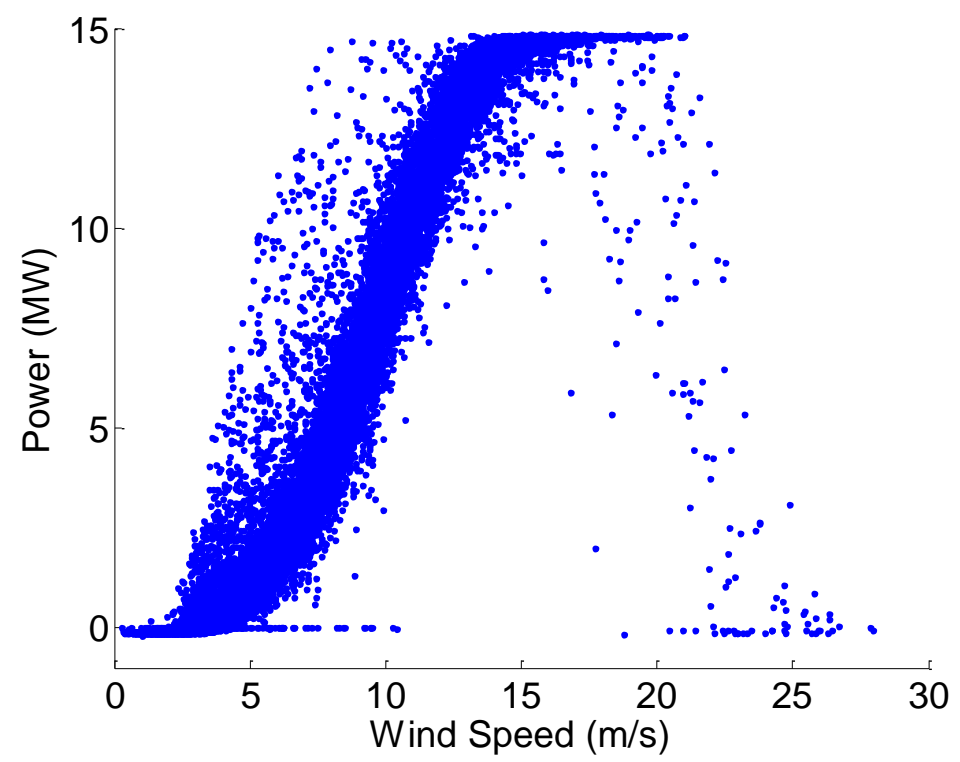

Fig. 10. Scatter Plot of Wind Velocity-Power

A polynomial curve fitting method is applied to create power curve. One year period of available data is used to perform method applications. 7. order polynomial fit is selected as a fitting method. Matlab Curve Fitting toolbox is used to fit curve. Other method is mean bins, this method is specified in [14]. In this method averages of powers and wind speeds are calculated for each $0.5(\mathrm{~m} / \mathrm{s})$ wind speed bins. These values formed power curve. Comparison of these power curves is given in Fig. 11.

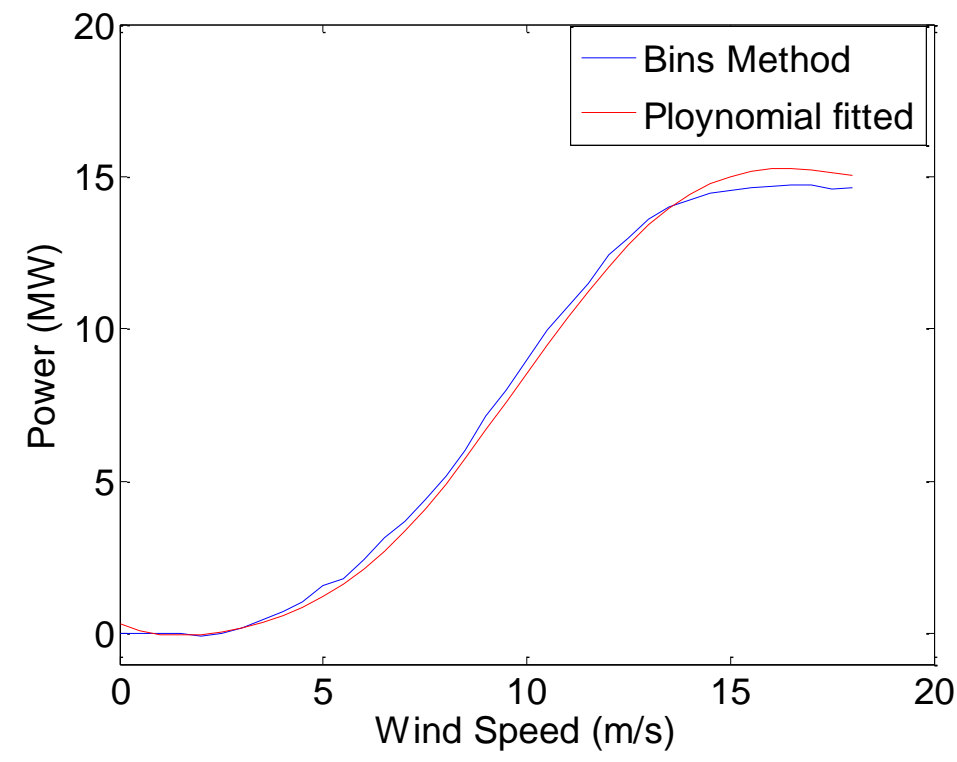

Fig. 11: Polynomial Fitted and Mean Bins Method Power Curves

Mean bins method power curve has smaller values near installed power output. It is the result of low power outputs of wind farm at rated wind speeds. These two methods have single input and single output. Effect of air density is not included. 
A new method is proposed to investigate effect of air density on power curve. It is well known that wind power has proportional relation between air density as given in (4). To reject the effect of measured air density on measured power, hourly measured power is divided to measured air density (5). Air density rejected values are used to calculate air density rejected power curve. After this process, calculated power curve is tested with measured data by multiplying it's output with hourly measured air density values as in equation (6). By applying this method air density effect is rejected during curve development phase and it is injected during test phase.

$$
\begin{aligned}
& P=\frac{1}{2} c \rho v^{3} \\
& P^{v}(v)=\frac{1}{2} c v^{3}=\frac{P_{m}(\rho, v)}{\rho_{m}} \\
& P=P c(v) \rho_{m}
\end{aligned}
$$

At the second phase of the method applications. Effect of air density on power curves is argued. Comparison of air density rejected power curves and others are given in Fig. 12 and Fig. 13.

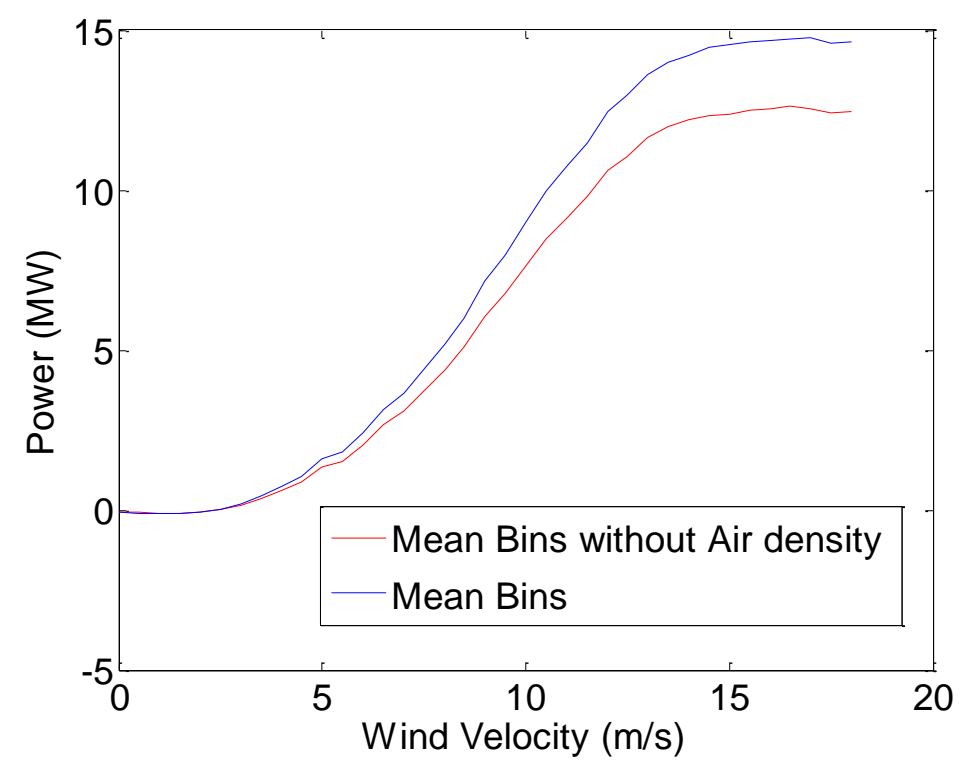

Fig. 12. Mean Bins and Mean Bins Without Air Density Method Power Curves 


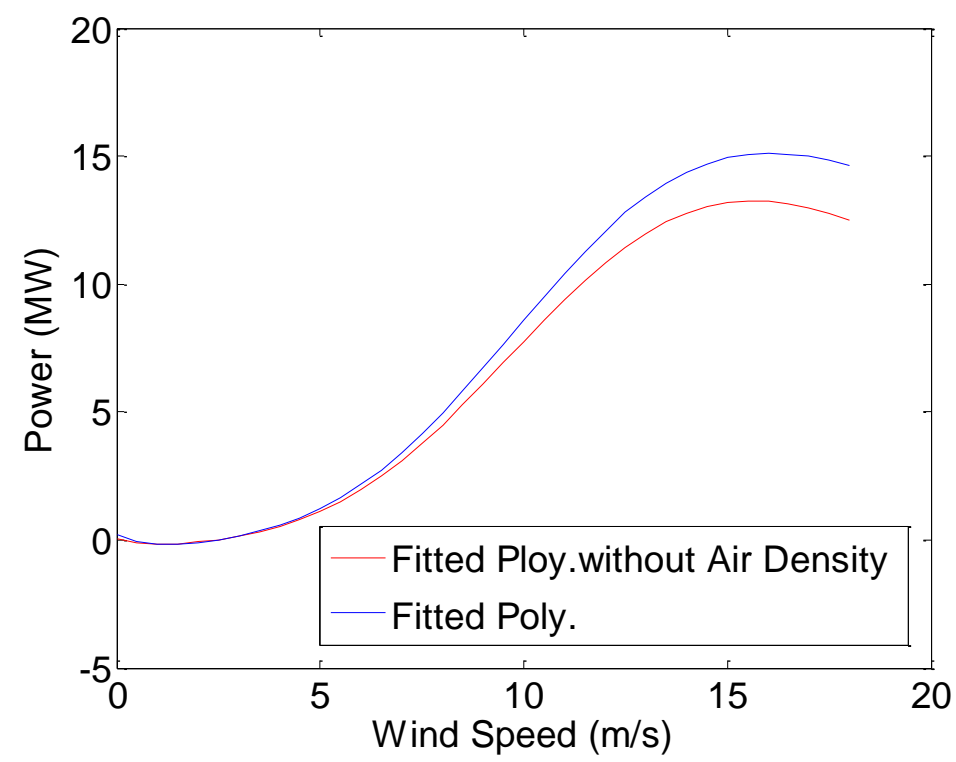

Fig. 13: Polynomial Fitting and Polynomial Fitting Without Air Density Method Power Curves

\section{PERFORMANCE TEST RESULTS}

In this section performances of methods are analyzed. One year period of available data is used to carry out performance tests. One year period is necessary to see seasonal effects on performances. Number of all available data is 21113 hours, it is nearly equal to 2.4 years. One year period was used to perform methods applications. Other year is used for performance tests. MAE of power curve outputs are calculated to evaluate performances. Table 1 summarizes MAE values. Test resuts showed that proposed air density rejection method improved performances.

Table 1: MAE Values of Methods

\begin{tabular}{|l|c|}
\hline Method & \% MAE \\
\hline Polynomial Fit. & 5.46 \\
\hline $\begin{array}{l}\text { Polynomial Fit. } \\
\text { Without Air density }\end{array}$ & 4.80 \\
\hline Mean Bins & 4.36 \\
\hline $\begin{array}{l}\text { Mean Bins } \\
\text { Without Air Density }\end{array}$ & 4.32 \\
\hline
\end{tabular}

\section{CONCLUSIONS}

This paper presents development of power curve using two different methods and air density effect on these methods. Power curves are developed and tested using real site measurements.

Power curves are very useful to detect anomalous operation of plants and to convert meteorological forecasts into power. So accuracy of power curve increases accuracies of these important calculations. Great number of researches on this topic focused on wind velocity-power relation. There is restricted number of studies in literacy that argues effect of air density on power curve. So results of this study are significant. On the other hand a new method is proposed to reject air density effect on power curve. This method is applied and performance improvements are assessed. 


\section{REFERENCES}

[1] Bitar, Eilyan Y., et al. "Bringing wind energy to market." Power Systems, IEEE Transactions on 27.3 (2012): 1225-1235.

[2] Evans, Annette, Vladimir Strezov, and Tim J. Evans. "Assessment of utility energy storage options for increased renewable energy penetration." Renewable and Sustainable Energy Reviews 16.6 (2012): 4141-4147.

[3] A. Picard, R. Davis, M. Gl“aser, and K. Fujii, “Revised formula for thedensity of moist air (cipm-2007),” Metrologia, vol. 45, pp 149-155, 2008

[4] Marvuglia, Antonino, and Antonio Messineo. "Monitoring of wind farms' power curves using machine learning techniques." Applied Energy 98 (2012): 574-583.

[5] Chang, Tian-Pau, et al. "Comparative analysis on power curve models of wind turbine generator in estimating capacity factor." Energy 73 (2014): 88-95.

[6] Lydia, M., Sahoo Subhendu Kumar, and G. E. P. Kumar. "Advanced algorithms for wind turbine power curve modeling." Sustainable Energy, IEEE Transactions on 4.3 (2013): 827-835.

[7] Olaofe, Zaccheus O., and Komla A. Folly. "Wind energy analysis based on turbine and developed site power curves: A case-study of Darling City." Renewable Energy 53 (2013): 306-318.

[8] Carrillo, C., et al. "Review of power curve modelling for wind turbines." Renewable and Sustainable Energy Reviews 21 (2013): $572-581$.

[9] Lydia, M., et al. "A comprehensive review on wind turbine power curve modeling techniques." Renewable and Sustainable Energy Reviews 30 (2014): 452-460.

[10] Milan, Patrick, Matthias Wächter, and Joachim Peinke. "Stochastic modeling and performance monitoring of wind farm power production." Journal of Renewable and Sustainable Energy 6.3 (2014): 033119.

[11] Farkas, Zeno. "Considering air density in wind power production." arXiv preprint arXiv:1103.2198 (2011).

[12] WAN, Y.; ELA, Erik; ORWIG, Kirsten. Development of an equivalent wind plant power curve. In: Proc. WindPower. 2010. p. 1-20.

[13] Compatibility, Electromagnetic. Part 4: 30: Testing and measurement techniques-Power quality measurement methods. IEC 61000-430 Std, 2003.

[14] Turbines, Wind. Part 12-1: Power performance measurements of electricity producing wind turbines; IEC TC/SC 88. IEC 61400-12-1, 2005.

[15] Ackermann, Thomas, ed. Wind power in power systems. John Wiley \& Sons, 2005. 